Marberg, K., Altmann, G., and Eshkol-Bruck, A. (1958). American fournal of Tropical Medicine and Hygiene, 7, 51 .

Noyes, H. E., Benjadol, Panyasri, and Taylor, R. L. (1969). Fournal of the Medical Association of Thailand, 52, 115.

Poovichit, B., Lexomboon, U., and Susilvorn, P. (1966). Fournal of the Department of Medical Service, 15, 557 .
Ramos-Alvarez, M., and Olarte, J. (1964). American fournal of Diseases of Children, 107, 218.

Reller, L. B. (1971). Applied Microbiology, 21, 21.

Riley, H. D., jun. (1968). Pediatric Clinics of North America, 15, 22.

Titze, W. (1971). Arzneimittel-Forschung, 21, 597.

Turk, D. C. (1960). Lancet, 2, 460 .

\title{
Withdrawal Depression in Obese Patients after Fenfluramine Treatment
}

\author{
JUDITH M. STEEL， MARION BRIGGS
}

British Medical fournal, 1972, 3, 26-27

\section{Summary}

Measurements of subjective feeling in 20 patients receiving fenfluramine alternating with placebo and in 19 patients receiving phentermine alternating with placebo indicated that depression of mood occurred four days after fenfluramine withdrawal but no such depression was seen with phentermine.

\section{Introduction}

All the common anorexic agents in current use are amphetamine cogeners having in common the phenylethylamine structure illustrated in the following examples:

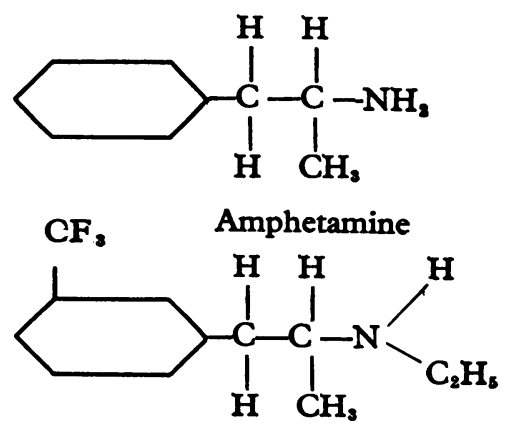

Fenfluramine

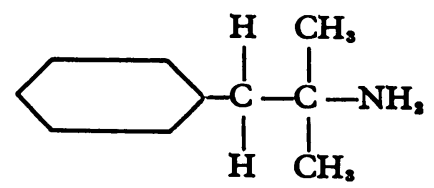

Phentermine

As many anorexic agents have some of the stimulant properties of amphetamine there has been considerable anxiety about their possible exploitation as drugs of abuse (Duncan and Munro, 1968; Advisory Committee Report, 1970). It is sometimes implied that if no side effects are stimulated by the central nervous system the drug will be free from this hazard. Such an assumption may be unwarranted, since addiction to barbitur-

Diabetic and Dietetic Department, Royal Infirmary, Edinburgh JUDITH M. STEEL, M.B., M.R.C.P., Research Registrar

Department of Psychiatry, University of Edinburgh, Royal Edinburgh Hospital

MARION BRIGGS, B.sc., Research Assistant ates and tranquillizers is well documented (Isbell, 1950) and compound preparations containing both an amphetamine and a barbiturate-for example, Drinamyl-are commonly used "drugs of abuse."

Fenfluramine is the most widely prescribed non-stimulant amphetamine derivative in this country. It has mild sedative properties and, with the exception of one unconfirmed report, has not been recognized as a drug of abuse (Brandon, 1969; Hawks, 1970) and has been successfully used to prevent withdrawal symptoms in patients dependent on methylamphetamine and dexamphetamine (Jones, 1971). However, Oswald et al. (1971) recorded consistent changes in mood after withdrawal of fenfluramine from patients who had taken it for the preceding 28 days or longer, depression being maximal on the fourth post-withdrawal day. Adverse or unpleasant effects on withdrawal indicate that the organism has become adapted to the drug in a manner which may lead to physical or psychological dependence on it.

The present study was undertaken to compare the effects on mood and appetite of fenfluramine and phentermine. The latter agent, having mild stimulatory effects, has been suspected of being taken for "kicks" (Duncan and Munro, 1968) though there are no confirmed reports of its abuse in this country (Advisory Committee's Report, 1970). A case has been reported from Ireland of a patient abusing several amphetamine-like drugs including phentermine (Murray, 1964) and another single case from the United States (Rubin, 1964).

\section{Design of Study}

The patients were obese women aged 20 to 60 years who were participating in a double-blind controlled trial of fenfluramine and phentermine in varying regimens as aids to weight reduction. Details of this trial will be reported elsewhere. Participants were asked to make a record, each evening, of their mood and subjective appetite during that day, using the linear self-rating record sheet described by Oswald et al. (1971) and discussed by Aitken (1969). At the end of the trial the records of two comparable groups of patients were analysed in detail. The first group consisted of 20 patients who received fenfluramine $20 \mathrm{mg}$ thrice daily for 28 days followed by placebo for 28 days. The second comprised 19 patients who took phentermine $30 \mathrm{mg}$ (as a slow-release resin preparation Duromine) each morning plus identical placebo tablets at midday and in the evening for 28 days, followed by placebo alone for 28 days.

\section{Results}

The mean ratings of mood and of appetite for the two groups over the whole 56-day period are shown in Figs. 1-4. It is clear that both agents were effective as appetite suppressants as compared with placebo. Neither caused any marked shift of mood 


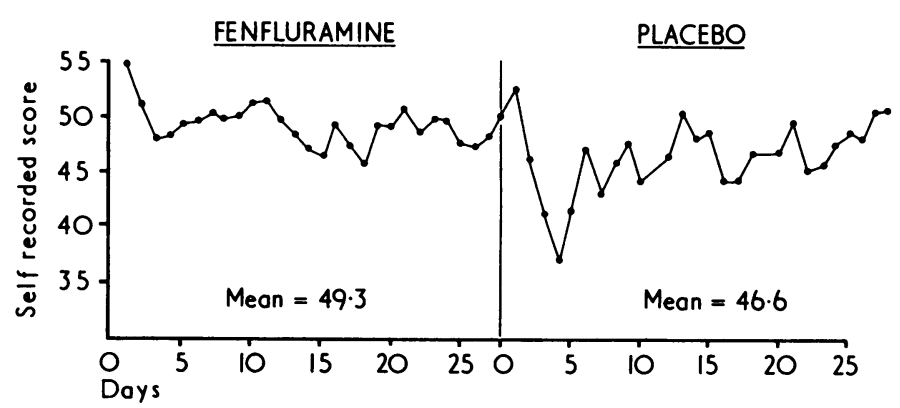

FIG. 1-Effect of fenfluramine and placebo on mood of 20 patients.

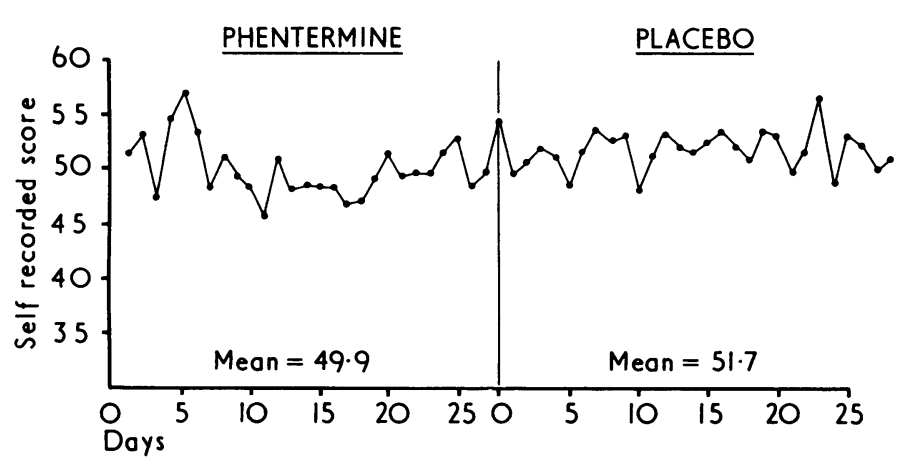

FIG. 2-Effect of phentermine and placebo on mood of 19 patients.

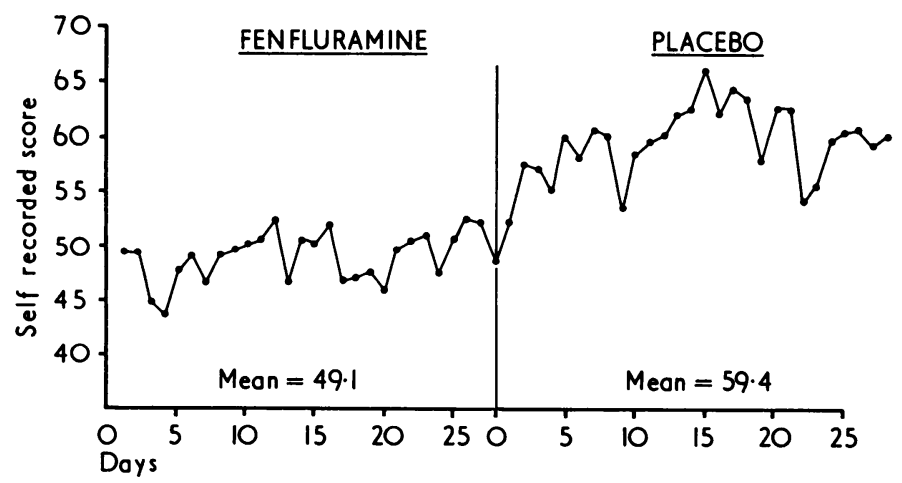

FIG. 3-Effect of fenfluramine and placebo on appetite of 20 patients.

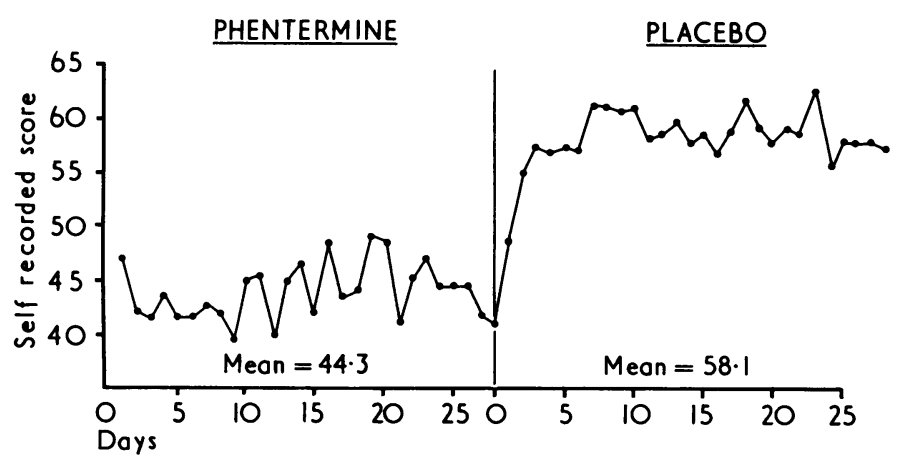

FIG. 4-Effect of phentermine and placebo on appetite of 19 patients. while the drug was being taken, although there seemed to be a rise in the self-rating score during the first week of phentermine administration. On withdrawal of fenfluramine a pronounced decline in mood was apparent, the lowest value being recorded on the fourth day after stopping the drug. A correlated $t$ test comparing the fourth day after withdrawal of fenfluramine with the 27th day after withdrawal showed the difference to be significant at the $1 \%$ level. There was no corresponding effect on stopping phentermine.

\section{Discussion}

This work confirms the withdrawal depression, on the fourth day after discontinuing fenfluramine, described by Oswald et al. (1971) and parallels the delay to a peak of withdrawal abnormality in cerebral electrophysiology (Lewis et al., 1971). Campbell (1971) showed that plasma concentrations of fenfluramine reach a plateau three to four days after starting the drug, and unpublished observations showed that a similar time is taken for the drug to be removed from the body (Campbell, personal communication).

Although withdrawal depression is an indication of dependence on a drug this does not necessarily mean that the drug is or will become a drug of abuse. Oswald et al. (1971) felt that the abuse potential of fenfluramine is low because it has unpleasant initial side effects, but many drugs of abuse seem to many subjects to have unpleasant initial side effects. One might expect that phentermine, in view of its stimulating side effects, would be more likely to become a drug of abuse; it is interesting that it does not produce withdrawal depression.

We should like to thank Riker Laboratories and Servier Laboratories for the supplies of phentermine (Duromine) and fenfluramine (Ponderax). We should also like to thank Dr. L. J. P. Duncan and the dieticians of the diabetic and dietetic department, Royal Infirmary, Edinburgh, for their helo and Dr. Ian Oswald, of the department of psychiatry, University of Edinburgh, for advice and encouragement

\section{References}

Advisory Committee Report (1970). The Amphetamines \& L.S.D. London, H.M.S.O.

Aitken, R. C. B. (1969). Proceeding of the Royal Society of Medicine, 62, 989.

Brandon, S. (1969). British Medical fournal, 4, 557.

Campbell, D. B. (1971). British fournal of Pharmacology, 43, 465.

Duncan, L. J. P., and Munro, J. F. (1968). Practitioner, 200, 167.

Hawks, D. V. (1970). British Medical fournal, 1, 238.

Isbell, H. (1950). Archives of Neurology and Psychiatry, 64, 1.

Jones, H. S. (1971). South African Medical fournal, 45, Suppl., p. 31.

Lewis, S. A., Oswald, I., and Dunleavy, D. L. F. (1971). British Medica fournal, 3, 67.

Murray, P. A. (1964). Fournal of the Jrish Medical Association, 54, 21.

Oswald, I, Lewis, S. A. Dunleavy, D. L. F., Brezinova, V., and Briggs, M. (1971). British Medical fournal, 3, 70

Rubin, R. T. (1964). American fournal of Psychiatry, 120, 1124. 